Acta Crystallographica Section B

Structural

Science

ISSN 0108-7681

Editor: Carolyn P. Brock

\title{
The crystal and molecular structure of cholest-4-en-6-one
}

\author{
L. R. Nassimbeni, J. C. Russell and G. M. L. Cragg
}

This electronic document was scanned from an archival copy of material deposited to accompany a paper published in an IUCr journal. In many cases the only accessible copy was a microfilm of a poor-quality original. 


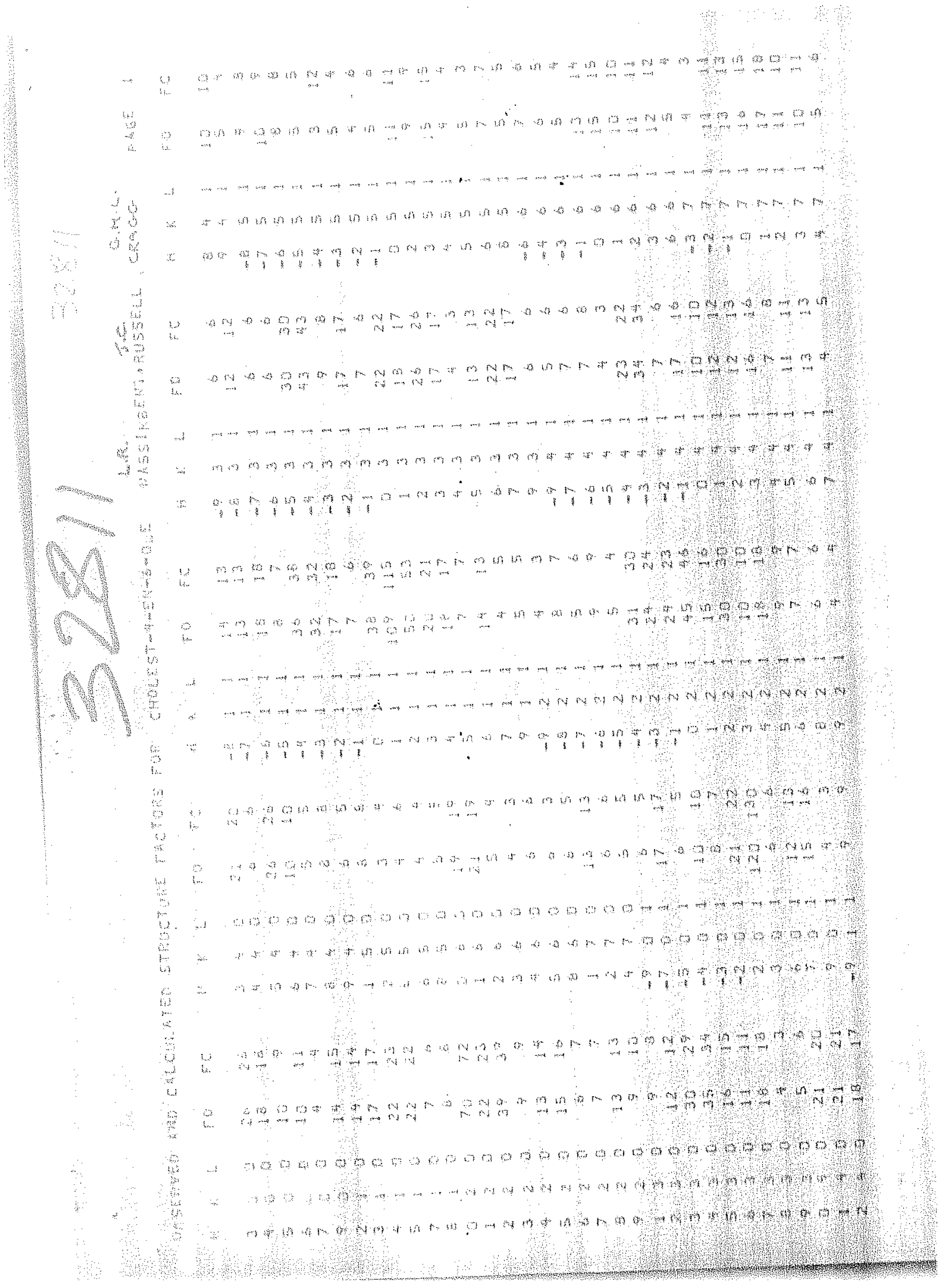




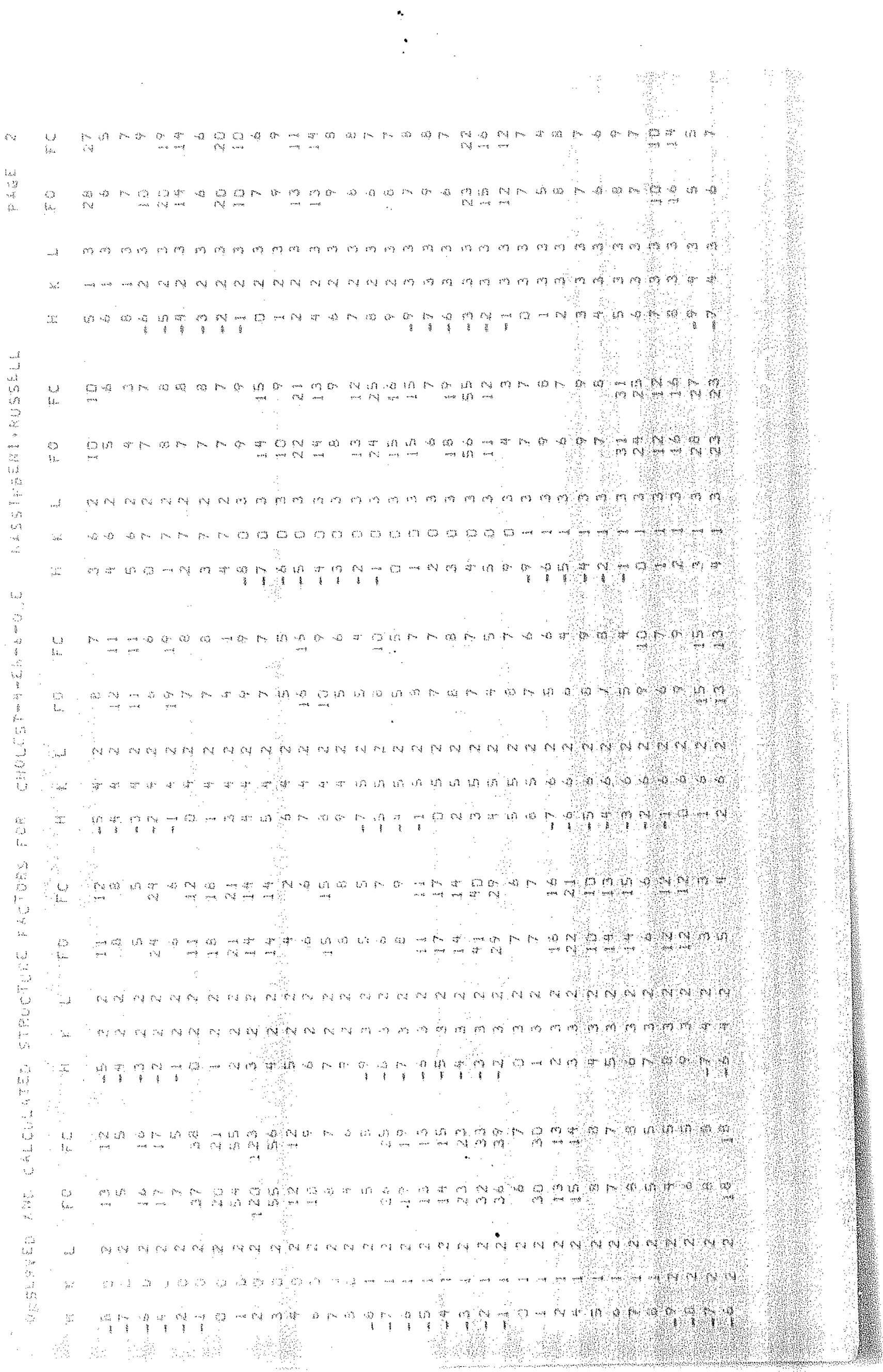




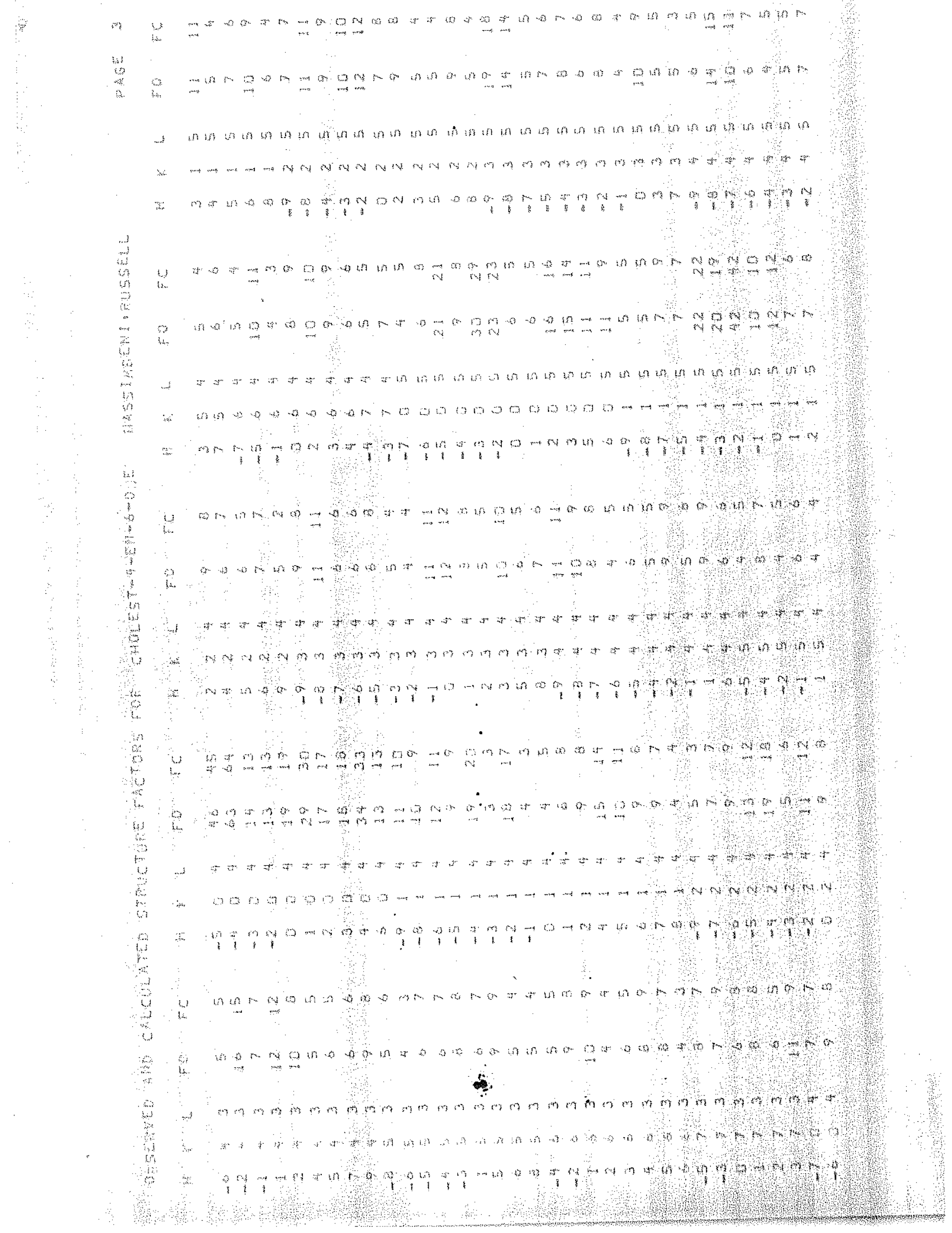




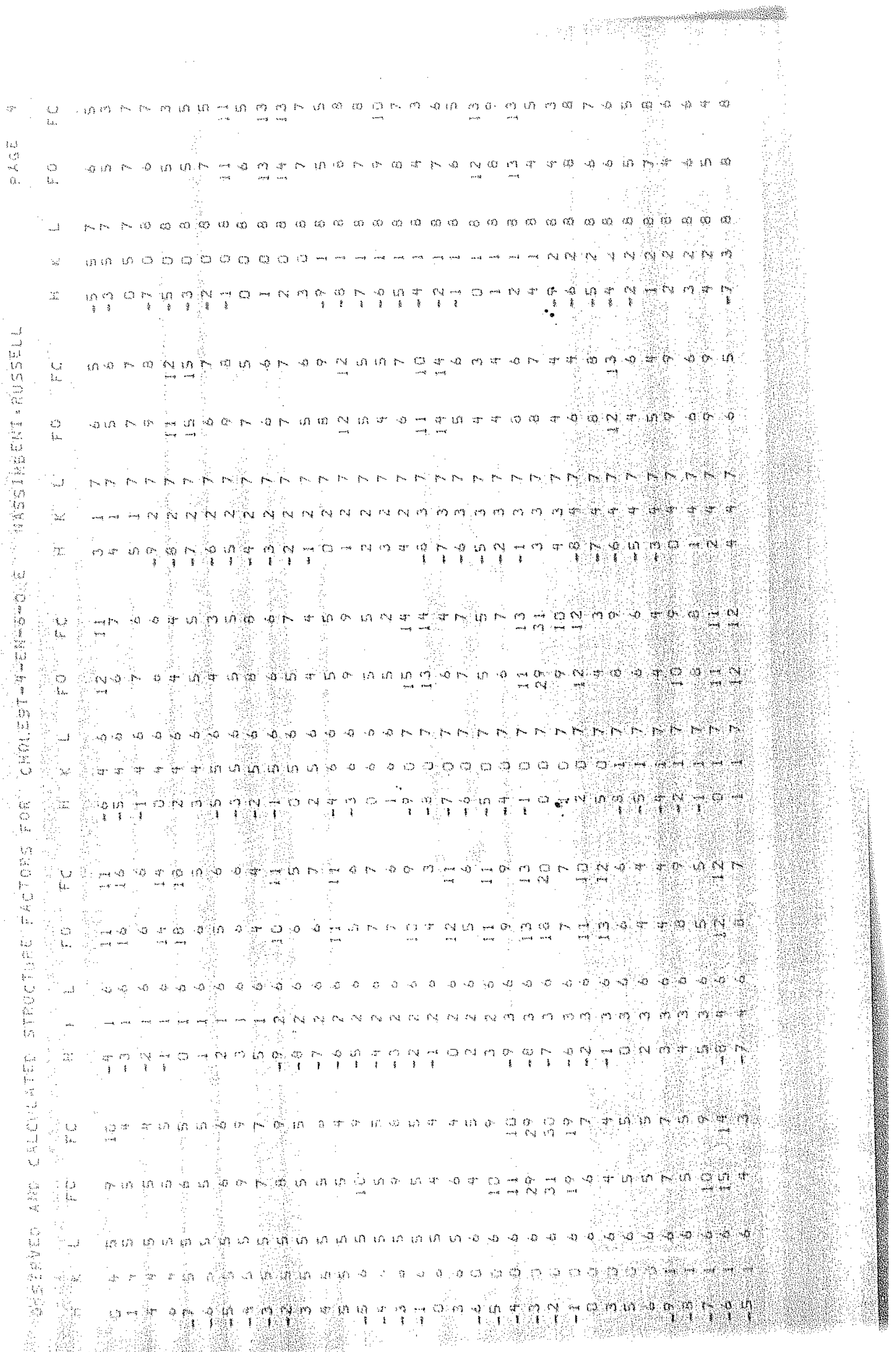




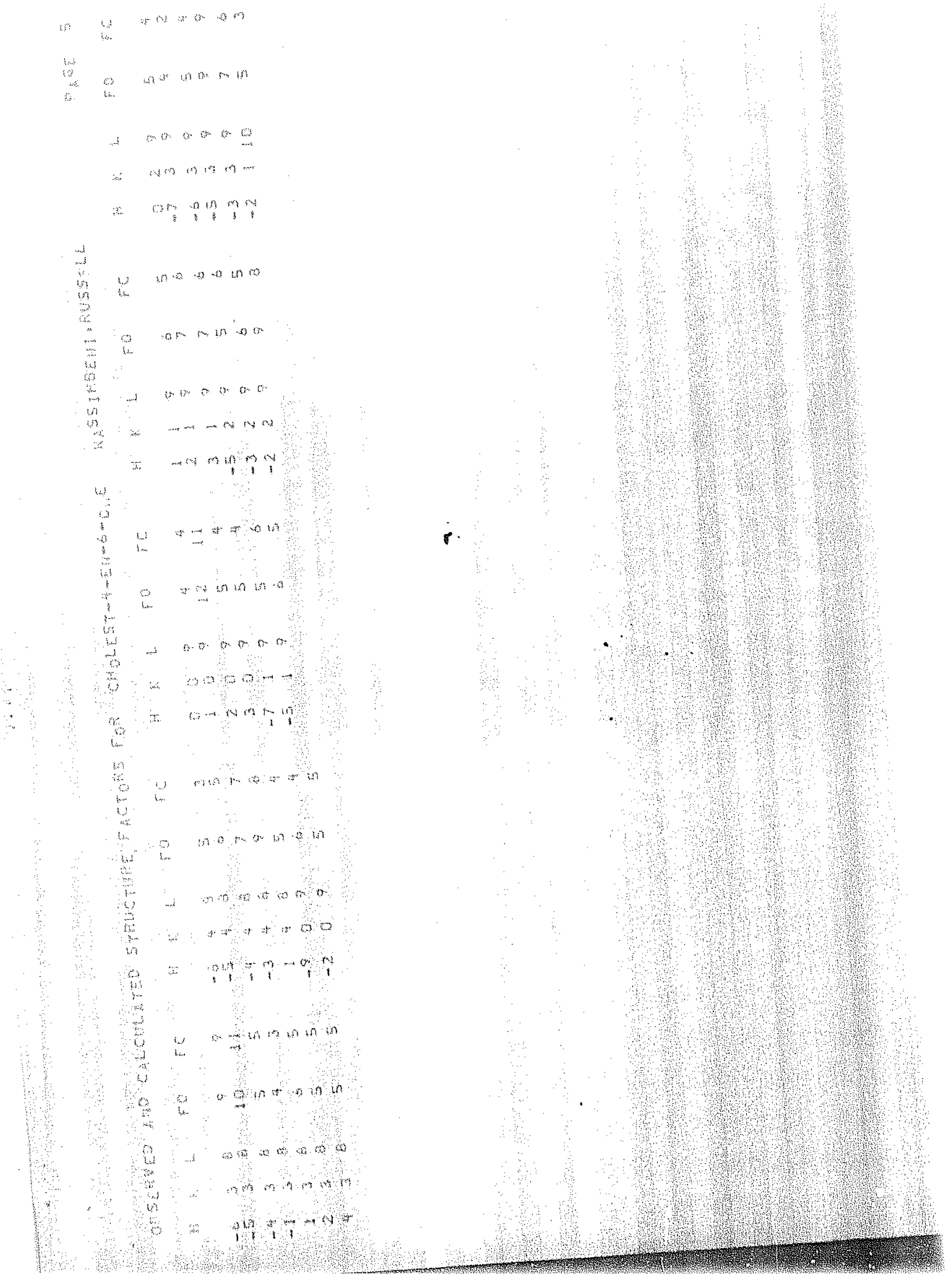




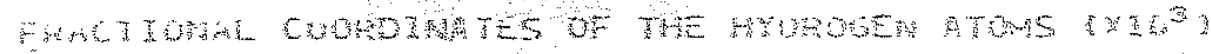

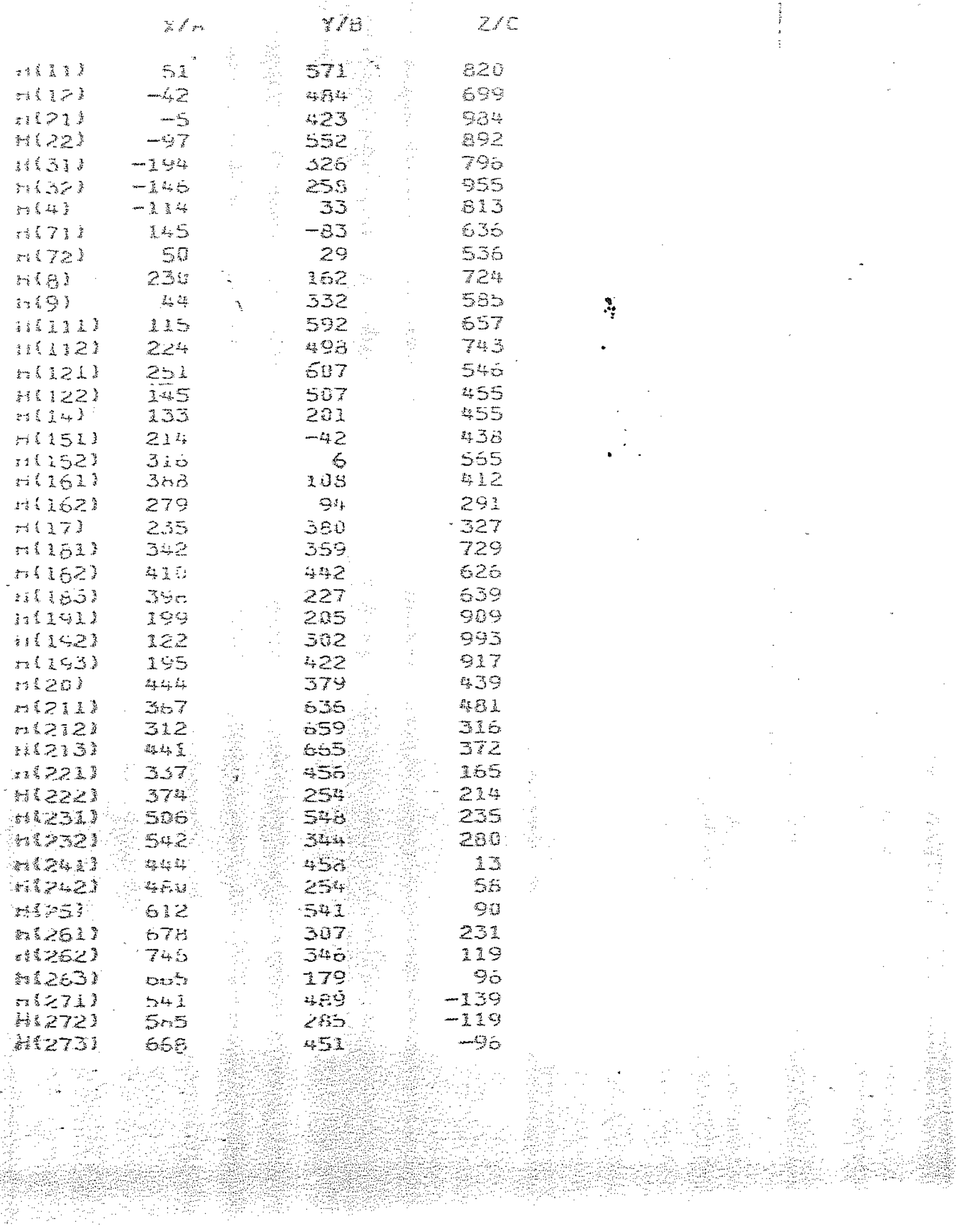




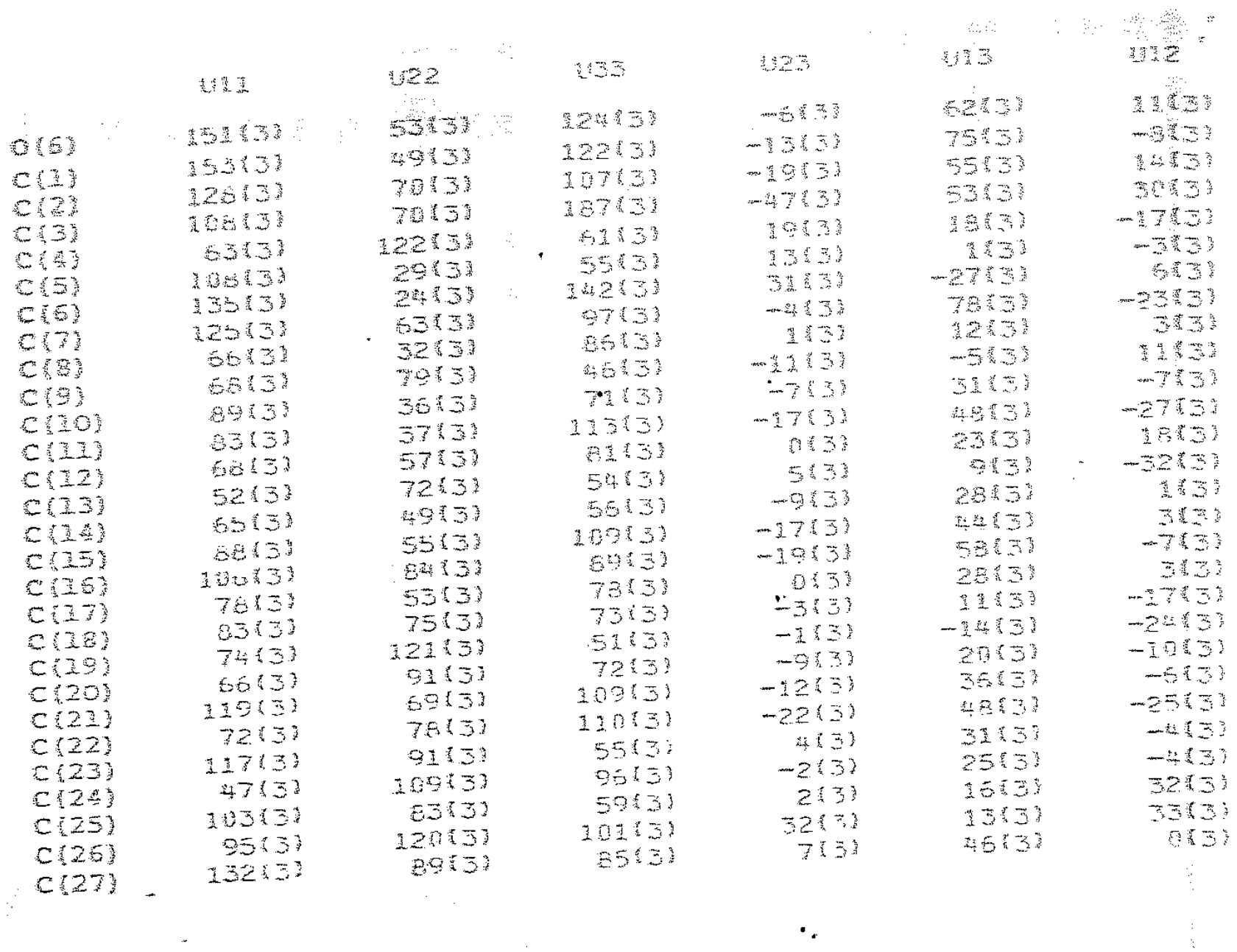

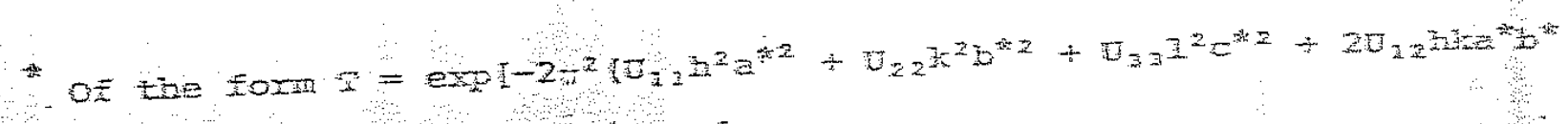

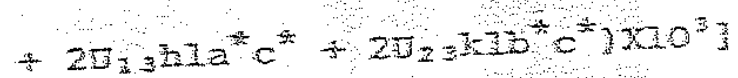

